Full Length Article

\title{
Establishment of a High-efficiency Genetic Transformation System of Cucumber (Cucumis sativus) using Csexpansin 10 (CsEXP10) Gene
}

\author{
Yongdong Sun*, Weirong Luo, Zhenxia Li, Yanhua Li and Lei Ni \\ School of Horticulture and Landscape Architecture, Henan Institute of Science and Technology, Xinxiang, Henan, \\ 453003, China \\ "For correspondence: sunyd2001@163.com
}

\begin{abstract}
Cucumber is one of the most important vegetable crops in the world. To establish an efficient genetic transformation system in cucumber, the role of different factors such as pre-cultivation time, acetosyringone concentration, infection time and cocultivation time that can influence the transformation, was evaluated. In addition, Csexpansin 10 (CsEXP10) gene was transformed into the cucumber genome to produce transgenic lines. The results showed that various optimal parameters such

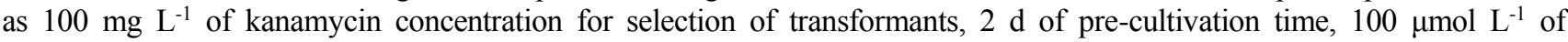
acetosyringone concentration, $15 \mathrm{~min}$ of infection time and $2 \mathrm{~d}$ of co-cultivation time were obtained using cotyledonary node explants. The rooting frequency observed on Murashige and Skoog (MS) medium supplemented with $0.2 \mathrm{mg} \mathrm{L}^{-1}$ indole acetic acid and $400 \mathrm{mg} \mathrm{L}^{-1}$ cefotaxime was found to be $100.00 \%$. The positive transgenic cucumber lines were identified using PCR analysis and GUS staining assay. It suggests that the genetic transformation system developed using cotyledonary node explants is efficient and successful in cucumber. (C) 2017 Friends Science Publishers
\end{abstract}

Keywords: Genetic transformation; Cucumber (Cucumis sativus L.); Csexpansin 10 (CsEXP10); Transformation efficiency

\section{Introduction}

Cucumber (Cucumis sativus L.) is an important vegetable crop and widely cultivated throughout the world. It is very rich in nutrients such as carbohydrates, amino acids, minerals and vitamins. In recent years, there has been a dramatic increase in the cultivation area of cucumber, especially under protected cultivation in China. However, under protected cultivation in the winter, environments stresses such as salt stress, low temperature, and weak light often affect cucumber growth and development, leading to high fruit deformation frequency and low yield.

Genetic engineering, an important technology for studying plant molecular biology, can be used to analyze gene functions and culture genetically modified plants, to improve the crop yield and quality. In addition, genetic engineering has some clear advantages such as a short breeding time and no changes in the desirable characteristics of plants, therefore, it is particularly valuable in genetic improvement of cucumber (Wang et al., 2015). During the last three decades, cucumber transformation techniques have undergone advances. The most effective method to transfer the desired genes into the cucumber genome is to use an Agrobacterium-mediated transformation approach (Trulson et al., 1986; Kose and Koç, 2003; Lin et al., 2011a). However, the genotype dependency, low- regeneration efficiency, and low reproducibility of this transformation system limit the use of transformation techniques in the genetic improvement of cucumber. Therefore, it is very essential to develop an efficient genetic transformation system for cucumber.

Expansin genes take part in the process of plant growth and development, and play an important role in morphogenesis, root hair growth (Lin et al., 2011b), pollination, flower development (Lee et al., 2001; Choi et al., 2006), fruit development (Rose et al., 1997; Brummell et al., 1999) and abscission. Csexpansin 10 (CsEXP10) gene was identified and cloned from young cucumber fruits by Sun et al. (2005), and was helpful for tomato fruits development in our previous study (Sun et al., 2016). In current study, an efficient and stable Agrobacteriummediated genetic transformation approach using cotyledonary node explants in cucumber with CsEXP10 gene has been developed, which can be successfully used for the introduction and functional analysis of desired genes.

\section{Materials and Methods}

\section{Plant Material}

Cucumber inbred lines 'Cs0601' was used as the experimental material. 'Cs0601' has only female flowers in the stem, seeds were supplied by School of Horticulture and 
Landscape Architecture, Henan Institute of Science and Technology, Xinxiang, China. Cucumber seeds were soaked for $4 \mathrm{~h}$ in water, surface-sterilized for $1 \mathrm{~min}$ with $70 \%(\mathrm{v} / \mathrm{v})$ ethanol followed by $20 \mathrm{~min}$ sterilization with $0.1 \%$ mercuric chloride. After rinsed in sterilized water for five times, surface sterilized seeds were cultured on the Murashige and Skoog (MS) medium supplemented with $7 \mathrm{~g} \mathrm{~L}^{-1}$ agar and 30 $\mathrm{g} \mathrm{L}^{-1}$ sucrose for $48 \mathrm{~h}$ at $28 \pm 1^{\circ} \mathrm{C}$ under darkness to promote seeds germination. Thereafter, germinated cucumber seeds were cultivated at $25 \pm 1^{\circ} \mathrm{C}$ for $5 \mathrm{~d}$ under a 16 -h photoperiod in a culture room. Cotyledonary nodes excised from 5-d-old sterilized cucumber seedlings without fully expanded cotyledons were used as explants for pre-cultivation, according to the techniques described by Li et al. (2016).

\section{Determination of Kanamycin Concentration}

In order to obtain the optimal kanamycin concentration for selection of transformants, cotyledonary nodes of cucumber were placed on MS medium supplemented with $2.0 \mathrm{mg} \mathrm{L}^{-1}$ 6-benzylaminopurine (6-BA) and $2.0 \mathrm{mg} \mathrm{L}^{-1} \mathrm{AgNO}_{3}$, containing different concentrations of kanamycin $(0,50,75$, 100 or $\left.125 \mathrm{mg} \mathrm{L}^{-1}\right)$ for $30 \mathrm{~d}$. Regeneration frequency and number of shoots were recorded.

\section{Pre-cultivation}

Cotyledonary node explants were pre-cultivated in the plates containing pre-cultivation medium (MS $+2.0 \mathrm{mg} \mathrm{L}^{-1} 6-\mathrm{BA}$ $+2.0 \mathrm{mg} \mathrm{L}^{-1} \mathrm{AgNO}_{3}$ ). The plates were kept in growth chamber $\left(25 \pm 1^{\circ} \mathrm{C}\right)$ under darkness for $0,1,2,3,4$ or $5 \mathrm{~d}$.

\section{Plasmid Vector}

Agrobacterium tumefaciens strain GV3101 harboring pCAMBIA-1301-CaMV35S constitutive promoter with GUS reporter gene was used for genetic transformation. CsEXP10 gene coding sequence ( $827 \mathrm{bp}$ ) was constructed downstream of the CaMV35S promoter as pCAMBIA1301-CsEXP10 (Fig. 1) described by Sun et al. (2015).

\section{Inoculum Solution Preparation}

A single colony of $A$. tumefaciens strain GV3101 harboring pCAMBIA-1301-CSEXP10 was grown on Yeast Extract Peptone (YEP) medium supplemented with $50 \mathrm{mg} \mathrm{L}^{-1}$ kanamycin and $50 \mathrm{mg} \mathrm{L}^{-1}$ rifampicin on incubator shaker

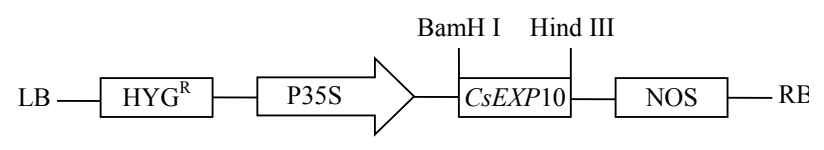

Fig. 1: Plant expression vector pCAMBIA1301-CsEXP10 used for genetic transformation

LB: T-DNA left border; $\mathrm{HYG}^{\mathrm{R}}$ : hygromycin; P35S: promoter from cauliflower mosaic virus; NOS: nos terminator; RB: T-DNA right border $\left(28 \pm 1^{\circ} \mathrm{C}, 250 \mathrm{rpm}\right)$ for $16 \mathrm{~h}$. Then the A. tumefaciens solution was diluted 1: 100 with YEP medium and was cultivated in YEP medium on incubator shaker $\left(28 \pm 1{ }^{\circ} \mathrm{C}\right.$, $250 \mathrm{rpm}$ ) for $4 \mathrm{~h}$.

\section{Co-cultivation and Selection}

Pre-cultivated cotyledonary node explants were immersed in inoculum solution of $A$. tumefaciens with different concentrations of acetosyringone $(0,100,200,300,400$ or $500 \mu \mathrm{mol} \mathrm{L}^{-1}$ ) and kept gentle shaking for 0-30 min. Then cotyledonary node explants were removed, dried with sterilized filter paper and placed to co-cultivation medium (MS $+2 \mathrm{mg} \mathrm{L}^{-1} 6-\mathrm{BA}+2 \mathrm{mg} \mathrm{L}^{-1} \mathrm{AgNO}_{3}+100 \mu \mathrm{mol} \mathrm{L}^{-1}$ acetosyringone) under darkness for $0,1,2,3,4$ or 5 days. After co-cultivation, cotyledonary node explants were transferred to selective medium (MS $+2 \mathrm{mg} \mathrm{L}^{-1} 6-\mathrm{BA}+$ $2 \mathrm{mg} \mathrm{L}^{-1} \mathrm{AgNO}_{3}+300 \mathrm{mg} \mathrm{L}^{-1}$ cefotaxime $+50 \mathrm{mg} \mathrm{L}^{-1}$ kanamycin). Regenerated putative transgenic cucumber shoots were cut and transferred to the different rooting mediums (Table 6). Rooted plantlets were then transferred to pots containing a sterile media of 1 turf : 1 vermiculite $(\mathrm{v} / \mathrm{v})$.

\section{PCR Detection of Transgenic Cucumber Lines}

Genomic DNA of the putative transgenic cucumber lines was extracted from the young leaves using Plant Genomic DNA Extraction Kit, SUN SHINE BIO. A pair of primer sequences: forward: 5'-ATGGCTTCTTCTCTTTCTCTCC3' and reverse: 5'-TGTAAAACGACGGCCAGT-3' were designed for PCR amplification. PCR amplification was carried out at $94^{\circ} \mathrm{C}$ for $3 \mathrm{~min}$; then 30 cycles of denaturation at $94^{\circ} \mathrm{C}$ for $30 \mathrm{~s}$, annealing at $54^{\circ} \mathrm{C}$ for $30 \mathrm{~s}$, extension at $72^{\circ} \mathrm{C}$ for $1 \mathrm{~min}$, with final extension at $72^{\circ} \mathrm{C}$ for $10 \mathrm{~min}$. PCR products of the expected size (500 bp) were separated on a $1.0 \%$ agarose gel by electrophoresis.

\section{GUS Activity Assay}

Expression of GUS gene in the young leaves of putative transgenic cucumber lines was analyzed with $\mathrm{X}$ glucuronide, as described by Sun et al. (2015).

\section{Data Analysis}

The data were analyzed by the Duncan's multiple range test at $\mathrm{P} \leq 0.05$, to determine significant differences. The statistical analyses were carried out with SPSS 17.0 software package. The data are expressed as mean \pm standard error.

\section{Results}

\section{Kanamycin Concentration}

Regeneration frequency and number of shoots from 


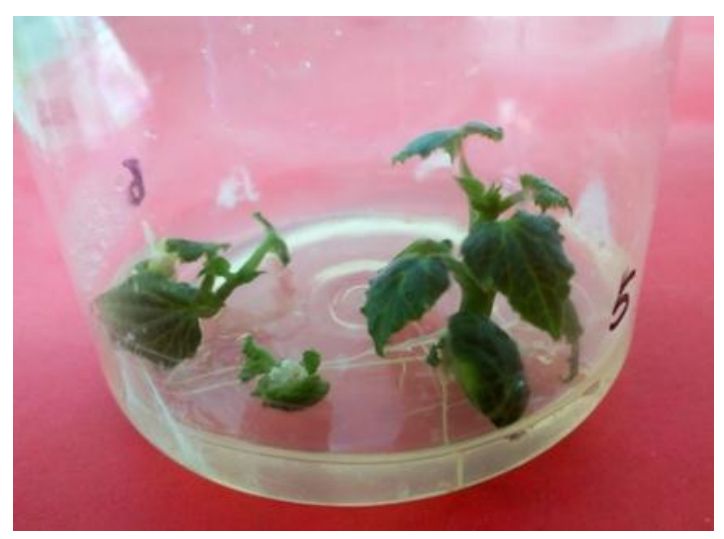

Fig. 2: Rooting of regenerated transgenic shoots

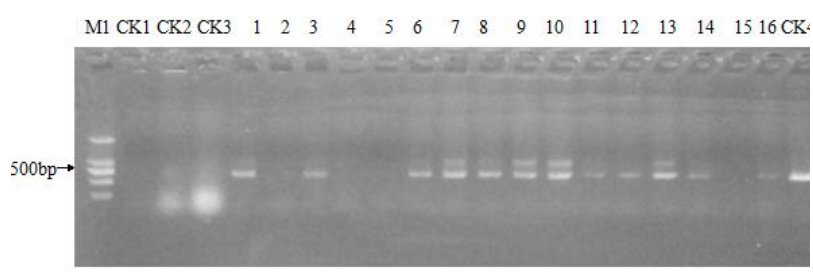

Fig. 3: PCR analysis of transgenic cucumber lines with a pair of primer sequences: forward: 5'ATGGCTTCTTCTCTTTCTCTCC-3' and reverse: 5'TGTAAAACGACGGCCAGT-3'

M1: DL2000 ${ }^{\mathrm{TM}}$ DNA Marker; CK1: Negative control; CK2-CK3: Agrobacterium tumefaciens solution; CK4: Plasmid DNA; 2, 4, 5, 15 : Non-transgenic lines; 1, 3, 6-14, 16: Transgenic lines

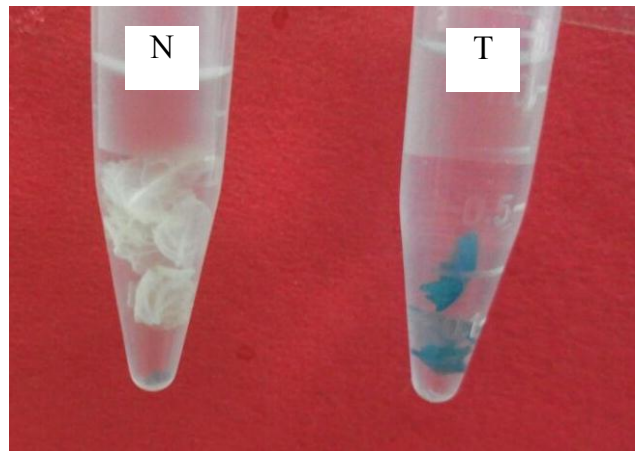

Fig. 4: GUS staining analysis of young leaves from cucumber

$\mathrm{N}$ : Non-transgenic line; T: Transgenic line

cotyledonary node explants were significantly inhibited by different kanamycin (Table 1). The inhabited frequency was increasing with the increasing concentrations of kanamycin. Regeneration frequency and number of shoots were $70.61 \%$ and 1.16 , respectively, when cotyledonary node explants were grown on medium without kanamycin. While, $20.29 \%$ of regeneration frequency and 0.14 of number of shoots were observed with $100 \mathrm{mg} \mathrm{L}^{-1}$ of kanamycin. Cotyledonary node explants showed complete bleaching and no regenerated shoots at $125 \mathrm{mg} \mathrm{L}^{-1}$ kanamycin. Based on these observations, $100 \mathrm{mg} \mathrm{L}^{-1}$ of kanamycin was considered optimal for the selection of transformants.

\section{Pre-cultivation Time}

Regeneration frequency and number of shoots varied with different pre-cultivation times (Table 2). Both regeneration frequency $(90.01 \%)$ and number of shoots $(1.72)$ were the highest when the cotyledonary node explants were precultivated for $2 \mathrm{~d}$. Therefore, $2 \mathrm{~d}$ of pre-cultivation was considered optimal for the cotyledonary node explants.

\section{Acetosyringone Concentration}

Acetosyringone has been used to enhance Agrobacteriummediated genetic transformation (Mishra et al., 2013; Manickavasangam et al., 2013; Gupta and Rahman, 2015). In this invesitgation, we observed the effect of different concentrations of acetosyringone in the A. tumefaciens inoculum solution on the transformation efficiency of the cucumber cotyledonary node explants (Table 3). Both regeneration frequency $(72.77 \%)$ and number of shoots (1.5) were the highest with $100 \mu \mathrm{mol} \mathrm{L}^{-1}$ of acetosyringone, significantly different from those with other concentrations. Therefore, $100 \mu \mathrm{mol} \mathrm{L}^{-1}$ of acetosyringone was essential for successful and high-efficiency transformation.

\section{Infection Time}

For efficient plant transformation, optimal A. tumefaciens infection time is one of the most important factors. Suitable infection time dramatically increases the efficiency of cucumber transformation. In our experiment, regeneration frequency and number of shoots were seen with different infection time $(0,5,10,15,20,25$ or $30 \mathrm{~min})$. Regeneration frequency and number of shoots varied with the infection time. No regeneration frequency and number of shoots were observed with 0 min of infection time. The optimal infection time for obtaining the highest regeneration frequency (99.31\%) and number of shoots (1.90) for the cotyledon node explants were $15 \mathrm{~min}$ (Table 4).

\section{Co-cultivation Time}

Different co-cultivation times $(0,1,2,3,4$ or 5 d) were also used as a parameter to investigate the transformation efficiency. We observed that the highest transformation efficiency was $2 \mathrm{~d}$ of co-cultivation. After $2 \mathrm{~d}$ of co-cultivation, the maximum regeneration frequency $(100 \%)$ and number of shoots (1.88) were observed. With the longer co-cultivation time, transformation efficiency decreased drastically. The lower regeneration frequency $(82.76 \%)$ and the lowest number of shoots $(0.55)$ were observed after $5 \mathrm{~d}$ of cocultivation (Table 5). 
Sun et al. / Int. J. Agric. Biol., Vol. 19, No. 3, 2017

Table 1: Effects of kanamycin on uninfected cotyledon node explants of cucumber

\begin{tabular}{llll}
\hline Kanamycin $\left(\mathrm{mg} \mathrm{L}^{-1}\right)$ & Number of explants & Regeneration frequency & Number of shoots/explant \\
\hline 0 & 24 & $70.61 \mathrm{a}$ & $1.16 \mathrm{a}$ \\
50 & 24 & $50.45 \mathrm{ab}$ & $0.81 \mathrm{~b}$ \\
75 & 24 & $42.83 \mathrm{bc}$ & $0.57 \mathrm{c}$ \\
100 & 24 & $20.29 \mathrm{~cd}$ & $0.14 \mathrm{~d}$ \\
125 & 24 & $0 \mathrm{~d}$ & $0 \mathrm{~d}$ \\
\hline
\end{tabular}

Note: Lower case letters indicate significant differences at $\mathrm{p}<0.05$

Table 2: Effects of pre-cultivation time on the regeneration frequency and number of shoots

\begin{tabular}{llll}
\hline Pre-cultivation time (d) & Number of explants & Regeneration frequency & Number of shoots/explant \\
\hline 0 & 24 & $0 \mathrm{c}$ & $0 \mathrm{c}$ \\
1 & 24 & $86.61 \mathrm{a}$ & $0.36 \mathrm{bc}$ \\
2 & 24 & $90.01 \mathrm{a}$ & $1.72 \mathrm{a}$ \\
3 & 24 & $88.29 \mathrm{a}$ & $0.34 \mathrm{bc}$ \\
4 & 24 & $86.03 \mathrm{a}$ & $0.44 \mathrm{bc}$ \\
5 & 24 & $80.31 \mathrm{a}$ & $0.56 \mathrm{~b}$ \\
\hline
\end{tabular}

Note: Lower case letters indicate significant differences at $\mathrm{p}<0.05$

Table 3: Effects of acetosyringone on the regeneration frequency and number of shoots

\begin{tabular}{lccc}
\hline Acetosyringone concentration $\left(\mu \mathrm{mol} \mathrm{L}^{-1}\right)$ & Number of explants & Regeneration frequency & Number of shoots/explant \\
\hline 0 & 24 & $32.83 \mathrm{ab}$ & $0.43 \mathrm{ab}$ \\
50 & 24 & $45.13 \mathrm{ab}$ & $0.60 \mathrm{ab}$ \\
100 & 24 & $72.77 \mathrm{a}$ & $1.50 \mathrm{a}$ \\
150 & 24 & $22.44 \mathrm{~b}$ & $0.62 \mathrm{ab}$ \\
200 & 24 & $48.61 \mathrm{ab}$ & $0.71 \mathrm{ab}$ \\
300 & 24 & $48.44 \mathrm{ab}$ & $0.36 \mathrm{~b}$ \\
500 & 24 & $47.63 \mathrm{ab}$ & $1.00 \mathrm{ab}$ \\
\hline
\end{tabular}

Note: Lower case letters indicate significant differences at $\mathrm{p}<0.05$

Table 4: Effects of infection time on the regeneration frequency and number of shoots

\begin{tabular}{lccc}
\hline Infection time (min) & Number of explants & Regeneration frequency & Number of shoots/explant \\
\hline 0 & 24 & $0 \mathrm{c}$ & $0 \mathrm{~d}$ \\
5 & 24 & $88.40 \mathrm{a}$ & $0.92 \mathrm{~b}$ \\
10 & 24 & $91.17 \mathrm{a}$ & $1.10 \mathrm{~b}$ \\
15 & 24 & $99.31 \mathrm{a}$ & $1.90 \mathrm{a}$ \\
20 & 24 & $93.35 \mathrm{a}$ & $0.89 \mathrm{~b}$ \\
25 & 24 & $50.31 \mathrm{~b}$ & $0.42 \mathrm{c}$ \\
30 & 24 & $23.08 \mathrm{bc}$ & $0 \mathrm{~d}$ \\
\hline
\end{tabular}

Note: Lower case letters indicate significant differences at $\mathrm{p}<0.05$

Table 5: Effects of co-cultivation time on the regeneration frequency and number of shoots

\begin{tabular}{lccc}
\hline Co-cultivation time (d) & Number of explants & Regeneration frequency & Number of shoots/explant \\
\hline 0 & 24 & $80.25 \mathrm{~b}$ & $1.12 \mathrm{~b}$ \\
1 & 24 & $75.24 \mathrm{~b}$ & $1.15 \mathrm{~b}$ \\
2 & 24 & $100.00 \mathrm{a}$ & $1.88 \mathrm{a}$ \\
3 & 24 & $98.16 \mathrm{ab}$ & $1.20 \mathrm{~b}$ \\
4 & 24 & $83.97 \mathrm{ab}$ & $0.88 \mathrm{bc}$ \\
5 & 24 & $82.76 \mathrm{a}$ & $0.55 \mathrm{c}$ \\
\hline Note: Lower case letters indicate significant differences at $\mathrm{p}<0.05$ & &
\end{tabular}

Table 6: Effects of different mediums on the rooting frequency

\begin{tabular}{|c|c|}
\hline Mediums & Rooting frequency $(\%)$ \\
\hline MS & $0 \mathrm{c}$ \\
\hline MS+300 mg L $\mathrm{m}^{-1}$ cefotaxime & $0 \mathrm{c}$ \\
\hline $1 / 2 \mathrm{MS}+300 \mathrm{mg} \mathrm{L}^{-1}$ cefotaxime & $0 \mathrm{c}$ \\
\hline $\mathrm{MS}+0.2 \mathrm{mg} \mathrm{L}^{-1} \mathrm{IAA}+400 \mathrm{mg} \mathrm{L}^{-1}$ cefotaxime & $100.00 \mathrm{a}$ \\
\hline $1 / 2 \mathrm{MS}+0.2 \mathrm{mg} \mathrm{L}^{-1} \mathrm{IAA}+400 \mathrm{mg} \mathrm{L}^{-1}$ cefotaxime & $83.13 \mathrm{~b}$ \\
\hline $\mathrm{MS}+0.2 \mathrm{mg} \mathrm{L}^{-1} \mathrm{NAA}+400 \mathrm{mg} \mathrm{L}^{-1}$ cefotaxime & $89.50 \mathrm{~b}$ \\
\hline
\end{tabular}

Note: Lower case letters indicate significant differences at $\mathrm{p}<0.05$ 


\section{Rooting Medium}

For rooting, regenerated transgenic cucumber shoots were placed on various mediums (Table 6). Rooting was observed on three mediums. The highest rooting frequency $(100.00 \%)$ was observed on MS medium supplemented with $0.2 \mathrm{mg} \mathrm{L}^{-1}$ indole acetic acid (IAA) and $400 \mathrm{mg} \mathrm{L}^{-1}$ cefotaxime. The rooting frequencies observed on MS medium, supplemented with $0.2 \mathrm{mg} \mathrm{L}^{-1} \alpha$-naphthaleneacetic acid (NAA) and 400 $\mathrm{mg} \mathrm{L}^{-1}$ cefotaxime, and on 1/2 MS medium, supplemented with $0.2 \mathrm{mg} \mathrm{L}^{-1}$ IAA and $400 \mathrm{mg} \mathrm{L}^{-1}$ cefotaxime, were $89.5 \%$ and $83.13 \%$, respectively. Roots obtained on the MS medium supplemented with $0.2 \mathrm{mg} \mathrm{L}^{-1} \mathrm{IAA}$ and $400 \mathrm{mg} \mathrm{L}^{-1}$ cefotaxime were thicker and longer than those on the other two mediums (Fig. 2); therefore, it was considered as the optimum rooting medium.

\section{Identification of Transgenic Plants}

To prove the genetic transformation system, PCR amplification of genomic DNA from putative transgenic cucumber lines with the specific primer pair was conducted. PCR products of the expected size (500 bp) were amplified from 12 transgenic cucumber lines, which gave the same size PCR products with the positive control (plasmid DNA), none was detected in the negative control and non-transgenic cucumber lines (Fig. 3). Young leaves from transgenic cucumber lines showed a dark blue colouration, indicating GUS gene expression, whereas the leaves from nontransgenic cucumber lines did not show positive results (Fig. 4).

\section{Discussion}

Functional analysis of genes underlying agricultural traits depends on an efficient genetic transformation system. In general, target genes are transferred into dicotyledonous plant genomes using the Agrobacterium-mediated transformation approach (Wang et al., 2015). Success of Agrobacterium-mediated transformation depends upon the regeneration frequency and number of shoots, which, in turn, depend upon the explant types, pre-cultivation time, acetosyringone concentration, infection time and cocultivation time. It is essential to optimize the above factors to establish an efficient genetic transformation system.

To evaluate the effects of pre-cultivation time and cocultivation time on the efficiency of genetic transformation, different times of pre-cultivation and co-cultivation were investigated using cotyledonary node explants. It was observed that $2 \mathrm{~d}$ of pre-cultivation and $2 \mathrm{~d}$ of co-cultivation were very effective in producing the highest cucumber regeneration frequency and number of shoots in cucumber. These findings of present study are in agreement with those found by Cardoza and Stewart (2003), Jonoubi et al. (2005), Khan et al. (2010), Wang et al. (2013) and Khan et al. (2013). The explants co-cultured for $2 \mathrm{~d}$ showed the highest regeneration frequency and number of shoots in current study. Previously, co-cultivation for $2 \mathrm{~d}$ was reported by Wang et al. (2013). In contrast, Mishra et al. (2013) reported that explants co-cultivated for $5 \mathrm{~d}$ showed the maximum transformation efficiency in rice. The dissimilarity in cocultivation time may be due to the differences in type and age of the explants used. In addition, Infection time is another essential factor in genetic transformation. Cotyledonary node explants infected for 15 min obtained the highest transformation efficiency in this study. In contrast to this result, Mashayekhi et al. (2008), Khan et al. (2010) and Tang et al. (2011) reported that 5-10 min of infection showed the maximum transformation efficiency.

Acetosyringone has been previously used to increase Agrobacterium-mediated transformation efficiency during infection (Mishra et al., 2013; Subramanyam et al., 2013). These studies reported that 20-200 $\mu \mathrm{mol} \mathrm{L}^{-1}$ of acetosyringone were optimal for transformation and different concentrations of acetosyringone were used for different explants. In our experiment, maximum transformation efficiency was found to be $100 \mu \mathrm{mol} \mathrm{L}^{-1}$ of acetosyringone.

Kanamycin has been previously used for selection of transformants in cucumber; however, different concentrations were used for different explants. $150 \mathrm{mg} \mathrm{L}^{-1}$ of kanamycin was used to select transformants by Wang et al. (2013), $200 \mathrm{mg} \mathrm{L}^{-1}$ of kanamycin was used by Oliveira $e t$ al. (2011), Mishra et al. (2013), and Alvarez and Ordás (2013). In present study, transformed cucumber lines were successfully selected at $100 \mathrm{mg} \mathrm{L}^{-1}$ of kanamycin.

Regenerated transgenic lines were identified using PCR analysis and GUS gene expression, non-transgenic cucumber lines did not show the positive results. These results indicated that plasmid vector had succeeded into the genome of the transgenic cucumber lines, demonstrating that this system could be successfully used for cucumber transformation.

\section{Conclusion}

An efficient Agrobacterium-mediated genetic transformation system using cotyledonary node explants in cucumber has been established by modulating of the different factors such as pre-cultivation time, acetosyringone concentration, infection time and co-cultivation time. And CsEXP10 gene was successfully transformed into the cucumber genome. The genetic transformation system developed was successful in cucumber and may be used for the functional analysis of desired genes in cucumber.

\section{Acknowledgements}

This work was sponsored by National Natural Science Foundation of China (31401860 and U1204322), Program for Science \& Technology Innovation Talents in Universities of Henan Province (17HASTIT040) and 
Xinxiang City Science \& Technology Innovation Talents Project (RC15007).

\section{References}

Alvarez, J.M. and R.J. Ordás, 2013. Stable Agrobacterium-mediated transformation of maritime pine based on kanamycin selection. World J., 2013: 1-9

Brummell, D.A., M.H. Harpster, P.M. Civello, J.M. Palys, A.B. Bennett and P. Dunsmuir, 1999. Modification of expansin protein abundance in tomato fruit alters softening and cell wall polymer metabolism during ripening. Plant Cell, 11: 2203-2216

Cardoza, V. and C. Stewart, 2003. Increased Agrobacterium-mediated transformation and rooting efficiencies in canola (Brassica napus L.) from hypocotyl segment explants. Plant Cell Rep., 21: 599-604

Choi, D., H.T. Cho and Y. Lee, 2006. Expansins: expanding importance in plant growth and development. Physiol. Plant, 126: 511-518

Gupta, V. and L.U. Rahman, 2015. An efficient plant regeneration and Agrobacterium-mediated genetic transformation of Tagetes erecta. Protoplasma, 252: 1061-1070

Jonoubi, P., A. Mousavi, A. Majd, A.H. Salmanian, M.J. Javaran and J. Daneshian, 2005. Efficient regeneration of Brassica napus L. hypocotyls and genetic transformation by Agrobacterium tumefaciens. Biol. Plant., 49: 175-180

Khan, I., M.S. Khan, M. Ilyas, H. Rajab, S.H. Shah and A. Jalal, 2013. Genetic Transformation of Brassica napus with the Antifungal chitinase Gene. Int. J. Agric. Biol., 15: 933-938

Khan, M., A. Robin, M. Nazim-Ud-Dowla, S. Talukder and L. Hassan, 2010. Agrobacterium-mediated genetic transformation of two varieties of Brassica: optimization of protocol. Bangl. J. Agric. Res., 34: 287-301

Kose, E. and N.K. Koç, 2003. Agrobacterium-mediated transformation of cucumber (Cucumis sativus L.) and plant regeneration. Biotechnol. Biotechnol. Eq., 17: 51-62

Lee, Y., D. Choi and H. Kende, 2001. Expansins: ever-expanding numbers and functions. Curr. Opin. Plant Biol., 4: 527-532

Li, Y.H., Y.D. Sun, W.R. Luo and L. Ni, 2016. Effects of various explants and hormone combinations on in vitro regeneration in cucumber. Chem. Eng. T., 51:31-36

Lin, C., H.S. Choi and H.T. Cho, 2011a. Root hair specific EXPANSIN A7 is required for root hair elongation in Arabidopsis. Mol. Cells, 31: 393-397

Lin, Y.T., C.W. Lin, C.H. Chung, M.H. Su, H.Y. Ho, S.D. Yeh, F.J. Jan and H.M. Ku, 2011b. In vitro regeneration and genetic transformation of Cucumis metuliferus through cotyledon organogenesis. HortScience, 46: 616-621
Mashayekhi, M., A. Shakib, M. Ahmad-Raji and K. Ghasemi Bezdi, 2008. Gene transformation potential of commercial canola (Brassica napus L.) cultivars using cotyledon and hypocotyl explants. Afr. J. Biotechnol., 7: 4459-4463

Mishra, S., R.S. Sangwan, S. Bansal and N.S. Sangwan, 2013. Efficient genetic transformation of Withania coagulans (Stocks) Dunal mediated by Agrobacterium tumefaciens from leaf explants of in vitro multiple shoot culture. Protoplasma, 250: 451-458

Oliveira, Y., L. Adamuchio, J. Degenhardt-Goldbach, I. Gerhardt, J. Bespalhok, R. Dibax and M. Quoirin, 2011. Use of kanamycin for selection of Eucalyptus saligna genetically transformed plants. $B M C$ Proc., 5: 147

Rose, J.K., H.T. Lee and A.B. Bennett, 1997. Expression of a divergent expansin gene is fruit-specific and ripening-regulated. Proc. Natl. Acad. Sci. USA, 94: 5955-5960

Subramanyam, K., M. Rajesh, B. Jaganath, V. Amrithalingam, T. Jeevaraj, D. Elayaraja, K. Sirabalan, M. Manickavasangam and A. Ganapathi, 2013. Assessment of factors influencing the Agrobacterium mediated in planta seed transformation of brinjal (Solanum melongena L). Appl. Biochem. Biotechnol., 171: 450-468

Sun, Y.D., L. Ni, S.Y. Sun and W.R. Luo, 2016. Effects of expression of Csexpansin 10 (CsEXP10) gene on the growth and antioxidant enzymes activities of tomato. Oxidative Commun., 39: 1293-1299

Sun, Y.D., W.R. Luo, S.Y. Sun and L. Ni, 2015. Agrobacterium-mediated transformation of tomato (Solanum lycopersicum L.) using the expansin 10 (CsEXP10) gene. Genet. Mol. Res., 14: 16215-16221

Sun, Y.D., X.G. Zhang, R.X. Hou, S.Y. Guo and F. Hao, 2005. Identification of expanding-related genes from young fruit of cucumber after pollination. J. Plant Physiol. Mol. Biol., 31: 403-408

Tang, G.X., K. Knecht, X.F. Yang, Y.B. Qin, W.J. Zhou and D. Cai, 2011. A two-step protocol for shoot regeneration from hypocotyl explants of oilseed rape and its application for Agrobacterium-mediated transformation. Biol. Plant., 55: 21-26

Trulson, A.J. and E.A. Shahin, 1986. In vitro plant regeneration in the genus Cucumis. Plant Sci., 47: 35-43

Wang, J., S.J. Zhang, X. Wang, L.N. Wang, H.N. Xu, X.F. Wang, Q.H. Shi, M. Wei and F.J. Yang, 2013. Agrobacterium-mediated transformation of cucumber (Cucumis sativus L.) using a sense mitogen-activated protein kinase gene (CsNMAPK). Plant Cell Tiss. Org., 113: 269277

Wang, S.L., S.K. Seong, X.G. Ye, C.F. He, Y.K. Suk and S.C. Pil, 2015. Current status of genetic transformation technology developed in cucumber (Cucumis sativus L.). J. Integr. Agric., 14: 469-482

(Received 31 December 2016; Accepted 27 February 2017) 